\title{
Toward a Practical, Two-Step Process for Molnupiravir from Cytidine
}

\author{
Dinesh J. Paymode, ${ }^{\dagger}$ N. Vasudevan, ${ }^{\dagger}$ Saeed Ahmad, Appasaheb L. Kadam, Flavio S.P. Cardoso, \\ Justina M. Burns, Daniel W. Cook, Rodger W. Stringham, David R. Snead*
}

Medicines For All Institute, 737 N 5th St., Box 980100, Richmond, Virginia 23298

\begin{abstract}
A two-step synthesis of molnupiravir (1) is presented. This work focuses on the development of practical reaction and purification conditions toward a manufacturing route. The sequence commences from highly available cytidine (2), and molnupiravir is formed through direct hydroxamination of the cytosine ring and esterification of the sugar's primary alcohol without use of protecting or activating groups. A highly crystalline hydrate of $N$-hydroxycytidine (3) resulted in an easily purified intermediate, and a practical, offthe-shelf enzyme was selected for the acylation. The yield was increased through a chemically-promoted, selective ester cleavage which converted a by-product, molnupiravir isobutyryl oxime ester (4), into the final API. Both reactions proceed in $>90 \%$ assay yield and crystallization procedures are used to afford intermediate and active pharmaceutical ingredient in purities above $99 \%$ with an overall yield of $60 \%$. Excellent throughput and sustainability is achieved by limiting the total concentration to 7 volumes of solvent in the course of the two reactions with an overall PMI of 41 including work-up and isolation. Environmentally friendly solvents, water and 2-methyl tetrahydrofuran, enhance sustainability of the operation.
\end{abstract}

\section{Introduction}

Molnupiravir (also known as EIDD-2801 and MK-4482) is emerging as a drug candidate of increasing interest based on its potential to treat COVID-19. Molnupiravir is currently under investigation in Phase II and III clinical trials after Merck licensed the compound from Ridgeback Biotherapeutics (NCT04405570, NCT04405739, NCT04575597, and NCT04575584). Further, animal studies show high promise. Molnupiravir showed broadspectrum antiviral activity against SARS-CoV-2 with reduced virus titer in mice, ${ }^{1}$ and completely blocked SARS-CoV-2 transmission in ferrets within $24 \mathrm{hr}$ of administering the medication. $^{2}$ From a pragmatic standpoint, molnupiravir is orally available and is structurally simple compared to remdesivir, making future manufacture considerably less complex. There are safety concerns related to the drug, and these should be answered by the pending clinical trials. ${ }^{3}$

We recently disclosed synthetic routes which detailed new bond-forming steps to reach molnupiravir (Fig. 1). ${ }^{4}$ The initial synthesis ${ }^{5}$ used for discovery purposes proceeded in $17 \%$ overall yield (yield of some steps not disclosed) over 4 discrete steps and sourced uridine (5) as the starting point rather than the more available and less expensive cytidine. ${ }^{6}$ The newer routes sought to improve yield, decrease step-count, and select lower cost starting materials, namely cytidine. Indeed, EIDD-2801 was made from cytidine in two steps with yields up to $75 \%$. These excellent preliminary results required refinement however. Intermediates and product were isolated by column chromatography, very high enzyme loadings were employed, reactions were run at highly dilute conditions as a result of limited substrate solubility, and results were only performed at $1 \mathrm{~g}$ scale.

Here we describe the improvements made which lead to a route with favourable manufacturing profile. Understanding byproducts and mechanism of formation allowed both reactions to reach yields

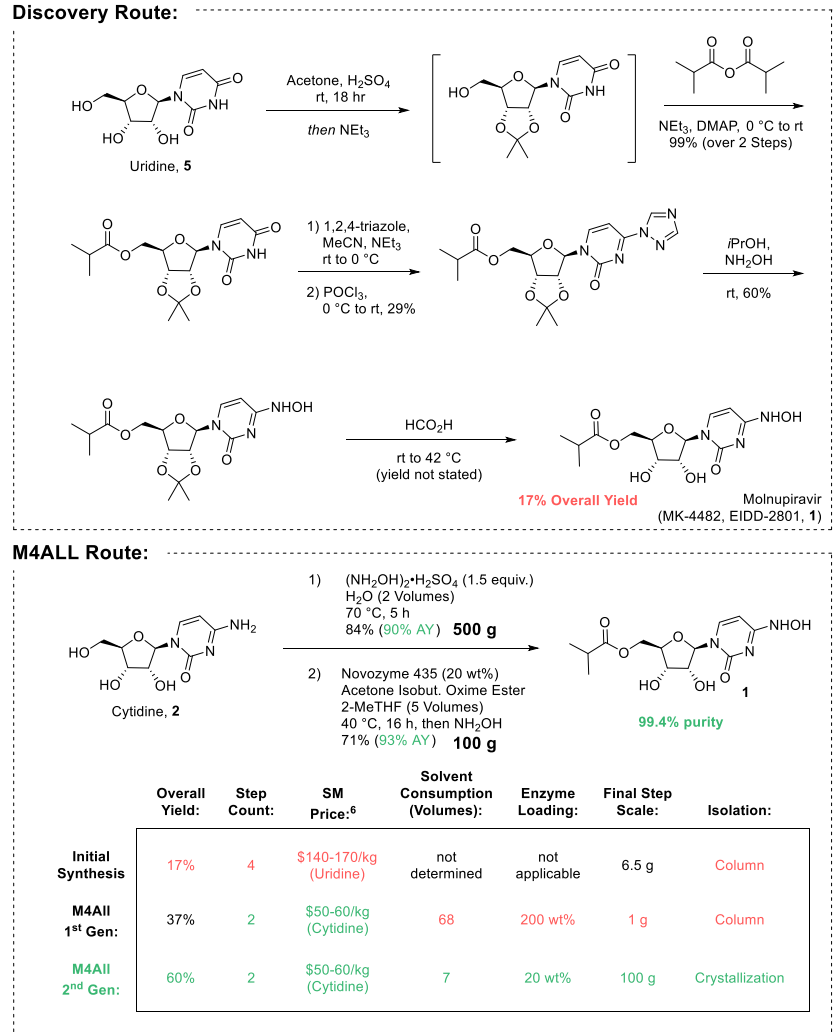

Figure 1: M4ALL's approach to molnupiravir from cytidine.

of $90 \%$ in solution. Ultimately, overall isolated yield was improved by $23 \%(60 \%$ from $37 \%)$ with product isolated by crystallization rather than chromatography. Solvent consumption during course of reaction was reduced ten-fold ( 7 volumes from 68 
volumes), and environmentally preferred solvents were selected (water and 2-methyltetrahydrofuran). An "off-the-shelf" enzyme (CAL-B) performed the acylation, and enzyme loading was reduced ten fold (200 wt $\% \rightarrow 20 \mathrm{wt} \%)$. Reactions were scaled to $500 \mathrm{~g}$ (NHC) and $100 \mathrm{~g}$ (molnupiravir), and final API was generated with purity of $99.4 \%$ with the majority of residuals being the active drug, NHC $(0.6 \%)$.

\section{- A Note on Cytidine Supply:}

Merck recently demonstrated an excellent route to molnupiravir. ${ }^{7}$ The use of an evolved enzyme to form the $N$ glycosidic bond of the nucleobase is particularly stimulating from an intellectual perspective. We are thrilled to see that others also find value in the CALB acylation of the ribose unit's primary alcohol and use of hydroxylamine for direct installation of the $N$ hydroxy functionality onto the nucleobase.

The assertion that cytidine is not available at multi-metric ton scale is not correct, however (Fig. 2). Cytidine is an important precursor to cytidine monophosphate (6) ${ }^{8}$ a compound consumed by the market in large quantity as a result of its applications in infant formula, ${ }^{9}$ food additives, ${ }^{10}$ animal feed industries, ${ }^{11}$ and as a precursor to citicoline, a dietary supplement. ${ }^{12}$ We proactively reached out to potential manufacturers early in our studies, and individual suppliers indicated capacity to supply $\geq 100$ MT of cytidine. ${ }^{13}$ Lending support to that claim, the observed volumes of cytidine monophosphate moving through only the Indian import marketplace reached 62 MT in 2020, a number which in fact exceeds that of ribose (24 MT).

The 4-step chemical route to cytidine described by Merck is not the only means of accessing cytidine, and it is not the shortest. In fact, there are two simple means of producing cytidine:

1. Recently, the single step syntheses of both cytidine and uridine from sugars were reported. Cytidine was made enzymatically at high concentrations by combining cytosine, ribose and a cytidine ligase. ${ }^{14}$ Uridine was made in high yield $(91 \%)$ via a chemical glycosylation of ribose with uracil promoted by phosphotungstic acid, negating the need for custom, evolved enzymes. ${ }^{15}$ The innovator company, Xianfeng Chemistry Co. (XFchem) is a large scale supplier. Takeda simply used glucose, corn liquor, and urea to build nucleoside from the ground up and furnish both cytidine ${ }^{16}$ and uridine, ${ }^{17}$ but the conditions were highly dilute. Significant variations of each strategy exist.

2. Classically, nucleosides are produced through digestion of natural materials, ribonucleic acids. Complete digestion results in production of the nucleosides including cytidine in quantitative yields. ${ }^{8 a-b, 18}$ The nucleosides can be separated using ion-exchange chromatography, or the nucleoside liquor can subsequently phosphorylated in the presence of yeast to yield the monophosphorylated nucleotides such as cytidine monophosphate. ${ }^{8 \mathrm{a}-\mathrm{d}, 19}$ Again, many updates have ensued since the original development of this technology in the 1930 s. $^{20}$

We thus feel quite comfortable in proposing cytidine as a starting point for the synthesis. The latent ability to supply cytidine appears to be high even though current market conditions favor consumption of the monophosphate.

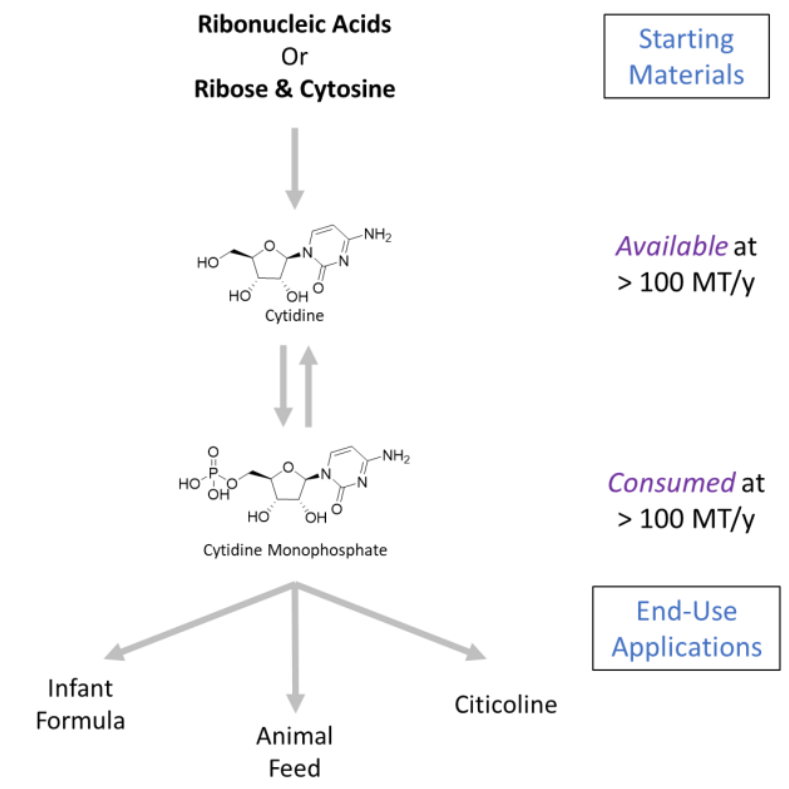

Figure 2: High volume end-use applications secures cytidine's availability.

\section{Results and discussion}

\section{- N-Hydroxycytidine: Reaction Screening and Impurity Profile}

In our first study we were pleased to see that pure $N$ hydroxycytidine $(7, \mathrm{NHC})$ could be recrystallized from a concentrated reaction mixture; however, the isolated yield of the transformation was lower than desired $(50 \%)$ and high solvent consumption limited material throughput.

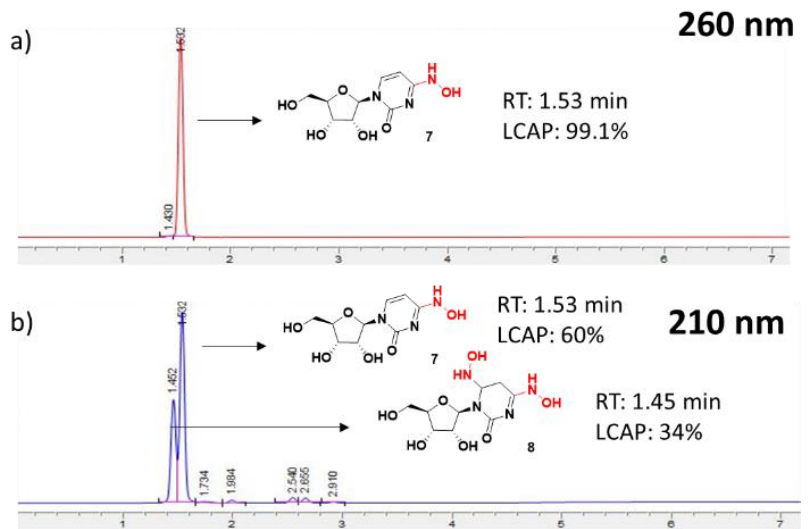

Figure 3: a) The HPLC chromatogram for the reaction at $260 \mathrm{~nm}$ shows high liquid chromatography area percent (LCAP). b) A byproduct is observed when monitoring the reaction at $210 \mathrm{~nm}$.

Monitoring the reaction at low wavelength $(210 \mathrm{~nm})$ revealed the presence of a second compound (8) in what appeared to be an otherwise clean transformation to product $(260 \mathrm{~nm})$ (Fig. 3). The byproduct turned out to be over-reaction of product with a second equivalent of hydroxylamine which adds to the cytosine ring in a 
1,4-fashion, thus destroying the conjugated system (Table 1). This explains the compound's low UV-activity, and the presence of the impurity is partially a result of using an excess of hydroxylamine. Alternative conditions employing hydroxylamine sulfate in an 2propanol/water mixture were explored. Surprisingly, cytidine was completely consumed and dihydroxamination was not observed. However, a new peak corresponding to uridine appeared in the HPLC chromatogram, revealing a second degradation pathway. Decreasing hydroxylamine sulfate equivalents exacerbated the problem.

Table 1: Optimization for synthesis of $N$-hydroxycytidine from cytidine. ${ }^{a}$

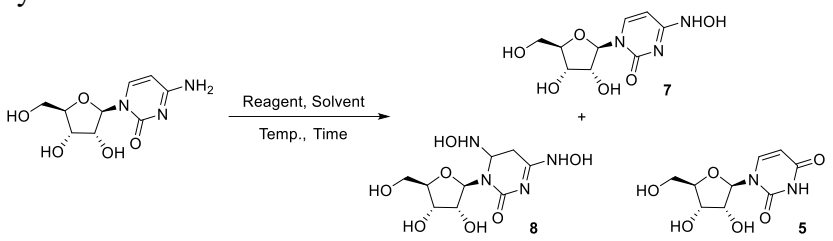

\begin{tabular}{|c|c|c|c|c|c|}
\hline \multirow[b]{2}{*}{ Entry } & \multirow{2}{*}{$\begin{array}{l}\text { Reagent } \\
\text { (Equiv.) }\end{array}$} & \multirow[b]{2}{*}{ Solvent (Vol.) } & \multicolumn{3}{|c|}{ LCAP } \\
\hline & & & 7 & 8 & 5 \\
\hline $1^{\mathrm{b}}$ & $\begin{array}{l}\mathrm{NH}_{2} \mathrm{OH} \cdot \\
\mathrm{HOAc}(3)\end{array}$ & $\mathrm{H}_{2} \mathrm{O}(20 \mathrm{~V})$ & 60 & 34 & - \\
\hline $2^{c}$ & $\begin{array}{l}\left(\mathrm{NH}_{2} \mathrm{OH}\right)_{2} . \\
\mathrm{H}_{2} \mathrm{SO}_{4}(4.5)\end{array}$ & $\begin{array}{c}70 \% \text { PrOH in } \\
\mathrm{H}_{2} \mathrm{O}(15 \mathrm{~V})\end{array}$ & 94 & - & 6 \\
\hline $3^{c}$ & $\begin{array}{l}\left(\mathrm{NH}_{2} \mathrm{OH}\right)_{2} . \\
\mathrm{H}_{2} \mathrm{SO}_{4}(0.5)\end{array}$ & $\begin{array}{c}70 \% \text { PrOH in } \\
\mathrm{H}_{2} \mathrm{O}(2 \mathrm{~V})\end{array}$ & 57 & - & 20 \\
\hline
\end{tabular}

${ }^{a}$ Reaction monitored at $210 \mathrm{~nm} .{ }^{\mathrm{b}}$ Reaction conditions: cytidine (200 mg, $0.77 \mathrm{mmol}), 40{ }^{\circ} \mathrm{C}, 48 \mathrm{hr}$. ${ }^{\mathrm{c}}$ Reaction conditions: cytidine (200 mg, 0.77 $\mathrm{mmol}), 70^{\circ} \mathrm{C}, 20 \mathrm{hr}$.

We wondered how these impurities might be avoided. Conditions were optimized for the biphasic isopropanol/water mixture with very high assay yield of NHC (Fig. 4). The best results were consistently obtained at 10 volumes of solvent and higher. We were pleased with the outcome but hoped for even higher concentration so as to minimize environmental impact and to maximize throughput.

We were curious how the percentage of water in isopropanol impacted the reaction (Fig. 5). In pure isopropanol, hydroxamination shutdown. However, water not only accelerated the reaction of cytidine, it also surprisingly suppressed uridine formation. Uridine levels peaked at $10-25 \%$ water in isopropanol. Perhaps rates of uridine and $\mathrm{NHC}$ formation are competitive at this cosolvent ratio.

Further probing the system showed that, in water, the reaction to form NHC could be run at much higher concentrations (Fig. 6). Only 2 volumes of solvent gave results which matched those run at higher dilutions. In fact, increasing the amount of water solvent increased the levels of uridine. The reaction was completed quickly, within 5-6 hr. Allowing the reaction to run for longer times resulted in decomposition of $\mathrm{NHC}$ with rising levels of uridine. The presence of $\mathrm{NH}_{2} \mathrm{OH} \cdot \mathrm{H}_{2} \mathrm{SO}_{4}$ appears to be important in the generation of uridine. NHC or cytidine in pure water do not form $\mathbf{5}$, unlike $\mathbf{3}$ heated in water with hydroxylamine.

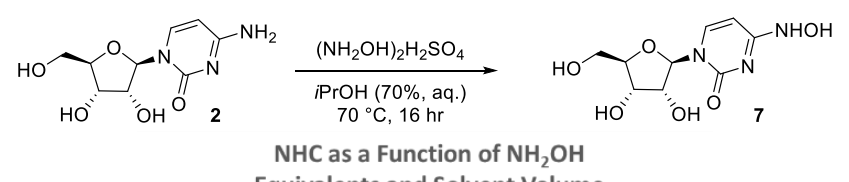

Equivalents and Solvent Volume

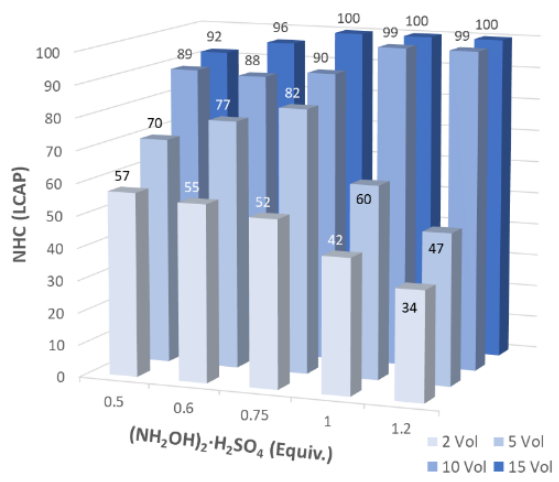

Figure 4: Excellent yield upon reaction optimization in $70 \%$ aqueous 2 propanol required $\geq 10$ volumes of solvent.

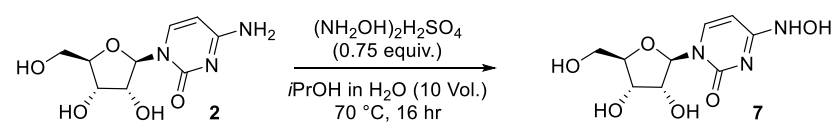

Impact of Water Content

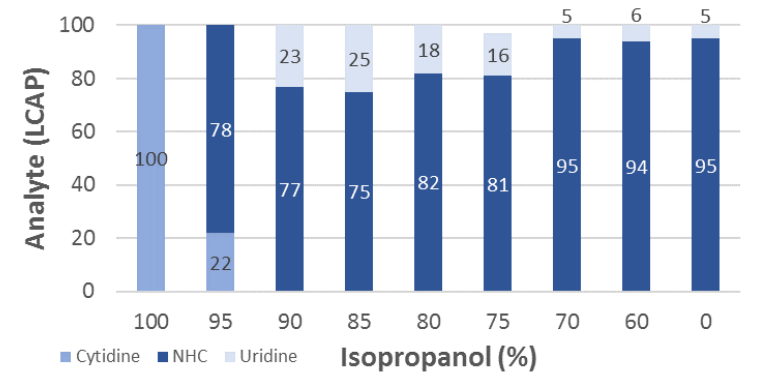

Figure 5: Probing reaction outcome as a function of water content revealed that reaction runs best in pure water.
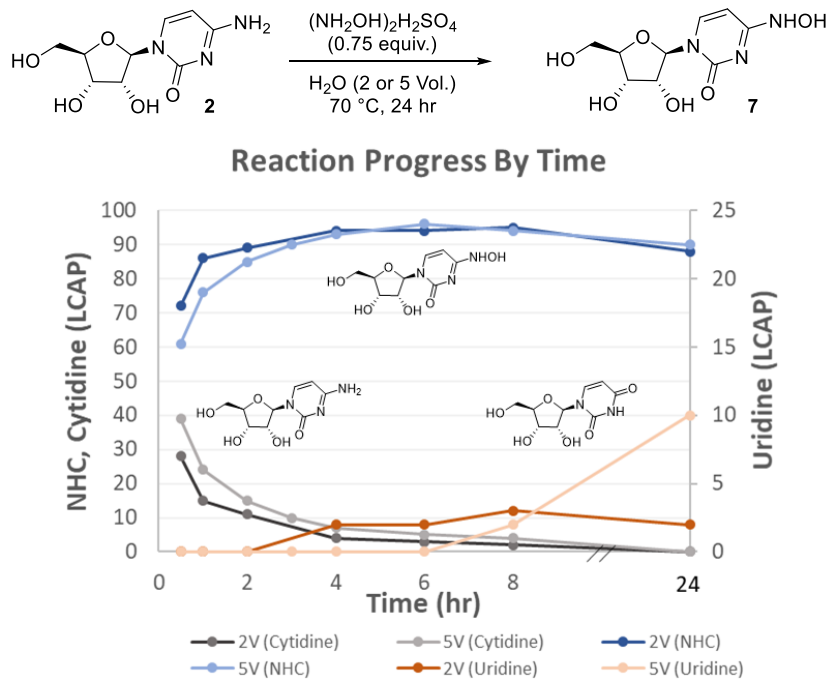

Figure 6: Running the reaction for too long results in increased uridine content. More concentrated conditions decrease uridine levels. 
- N-Hydroxycytidine: Purification and Isolation of the Hydrate

We next worked to increase scale and develop purification protocols, having optimized the reaction for maximum yield and minimal impurity formation, reaction time, and solvent consumption. Fortunately, the NHC appeared to be of limited solubility in water which could perhaps be used for direct isolation of product from reaction mixture. When we increased scale to the gram level, we noticed that the reaction started as a slurry, quickly became homogeneous $(<1 \mathrm{hr})$, and then again became a slurry, even at $70{ }^{\circ} \mathrm{C}$ (Table 2). To isolate the product, the reaction mixture was simply cooled to $4{ }^{\circ} \mathrm{C}$ and then filtered and washed.

Table 2: $1 \mathrm{~g}$ scale reactions and isolation of $\mathrm{NHC}^{\mathrm{a}}$

\begin{tabular}{|c|c|c|c|c|c|c|}
\hline \multirow[b]{2}{*}{ Entry } & \multirow[b]{2}{*}{$\begin{array}{c}\left(\mathrm{NH}_{2} \mathrm{OH}\right)_{2} \\
\mathrm{H}_{2} \mathrm{SO}_{4} \text { (eq.) }\end{array}$} & \multirow[b]{2}{*}{$\begin{array}{c}\mathrm{H}_{2} \mathrm{O} \\
\text { (Vol.) } \\
\end{array}$} & \multicolumn{2}{|c|}{$\begin{array}{c}\text { LCAP } \\
\text { (cytidine/NHC) }\end{array}$} & \multirow[b]{2}{*}{$\begin{array}{c}\text { Purity } \\
(\%)^{b}\end{array}$} & \multirow[b]{2}{*}{$\begin{array}{l}\text { Yield } \\
(\%)^{\mathbf{c}}\end{array}$} \\
\hline & & & $\begin{array}{c}\text { After } \\
\mathbf{3 h}\end{array}$ & $\begin{array}{c}\text { After } \\
6 \mathrm{~h} \\
\end{array}$ & & \\
\hline 1 & 0.75 & 2 & $16 / 84$ & - & 81 & 70 \\
\hline 2 & 0.75 & 5 & $21 / 79$ & $13 / 87$ & 84 & 82 \\
\hline 3 & 1.5 & 2 & $8 / 92$ & - & 85 & 84 \\
\hline 4 & 1.5 & 5 & $11 / 89$ & $5 / 95$ & 87 & 82 \\
\hline
\end{tabular}

${ }^{a}$ Reaction Conditions: cytidine ( $\left.1 \mathrm{~g}, 4.08 \mathrm{mmol}\right),\left(\mathrm{NH}_{2} \mathrm{OH}\right)_{2} \mathrm{H}_{2} \mathrm{SO}_{4}, \mathrm{H}_{2} \mathrm{O}$, $70{ }^{\circ} \mathrm{C}$ and time. ${ }^{b}$ Purity assessed by qNMR. ${ }^{c}$ Yields are adjusted to qNMR purities.

Results were consistent at varying levels of hydroxylamine and solvent, but purity of NHC was lower than expected despite the appearance of nice white product crystals $(81-87 \mathrm{wt} \%$ by qNMR in DMSO-d6). In the course of reaction, no dihydroxamination product was observed and uridine levels were quite low. The direct drop crystallization product contained neither impurity, and the HPLC chromatogram showed 100\% LCAP (210 and $260 \mathrm{~nm}$ ). Suspecting that hydroxylamine sulfate salts might be the culprit leading to low weight $\%$ purity, the product was recrystallized in water, yet purity did not rise above $87 \mathrm{wt} \%$ (qNMR). Interestingly, though the LC traces showed no other organic compounds, the ${ }^{1} \mathrm{H}$ NMR of NHC recorded in DMSO- $d_{6}$ showed several minor peaks accounting for $5-6 \%$ relative to the major compound (Fig. 7).

This led us to wonder whether the apparent low purity was a function of NHC isomerization. Perhaps the $\mathrm{N}$-hydroxycytosine can exist as a tautomers of the amine and imine. This observation would be in-line with literature precedence. ${ }^{21}$ To explore this possibility a variable temperature (VT) NMR experiment was carried out, increasing temperature at intervals of $10{ }^{\circ} \mathrm{C}$ up to $70^{\circ}$ C. At elevated temperatures, the minor peak disappeared and the major peak grew in intensity. Further, spectra were recorded in protic media to disrupt hydrogen-bonding and isomerization. Indeed, in $\mathrm{D}_{2} \mathrm{O}$ and $\mathrm{MeOH}-d_{4}$ the minor product was not observed. Purity increased by the amount of the minor isomer, but still, the product was only $93 \mathrm{wt} \%$ pure. A commercial sample of $\mathrm{NHC}$ was subjected to the same analysis in deuterated DMSO, water and methanol, and the same effects were observed.

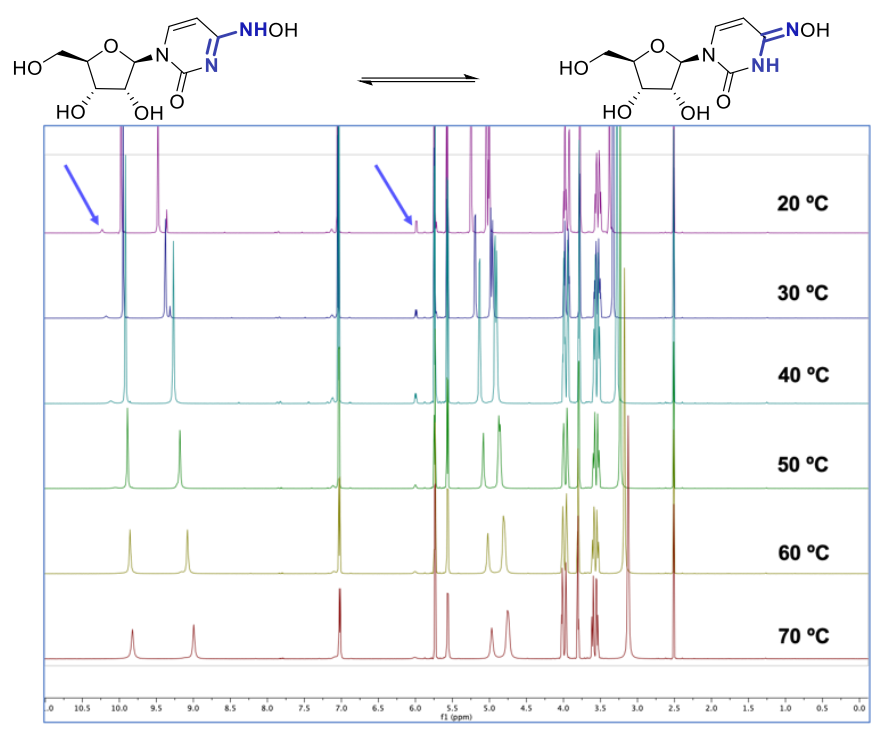

\begin{tabular}{ccccc} 
Entry & $\begin{array}{c}\text { Temp. } \\
\left({ }^{\circ} \mathrm{C}\right)\end{array}$ & $\begin{array}{c}\text { Major } \\
\text { isomer }(\%) \\
\mathbf{5 . 5 6} \mathbf{~ p p m})\end{array}$ & $\begin{array}{c}\text { Minor } \\
\text { isomer }(\%) \\
\mathbf{5 . 9 8} \mathbf{~ p m})\end{array}$ & $\begin{array}{c}\text { Combined } \\
\text { NHC (\%) }\end{array}$ \\
\hline 1 & 20 & 94.22 & 5.78 & 92.70 \\
2 & 30 & 94.19 & 5.81 & 92.32 \\
3 & 40 & 95.00 & 5.00 & 92.84 \\
4 & 50 & 95.87 & 4.13 & 92.91 \\
5 & 60 & 96.79 & 3.21 & 92.78 \\
6 & 70 & 97.86 & 2.14 & 92.79
\end{tabular}

Figure 7: Variable temperature (VT) NMR spectra of NHC in DMSO- $d_{6}$ shows a minor isomer which converts to the major isomer upon heating. Arrow in spectra points to minor isomer peaks.

We further wondered whether some inorganic material might be complexed with the sugar, accounting for the low purity, and thus sample was prepared for single crystal X-ray diffraction (Fig. 8). Two interesting conclusions were drawn from the X-ray analysis.

1. Water was complexed with $\mathrm{NHC}$ rather than inorganic metals. An intricate hydrogen-bond network formed with water's lone-pair and hydrogen atoms forming four hydrogen-bonds with NHC.

2. The amine/imine tautomerization issue was observed. Interestingly, the data showed that a single hydrogen atom occupied two positions at $\mathrm{H} 5$ and $\mathrm{H} 16$ in the ratio 76:24 respectively.

The seemingly low purity and unexplained mass contained in samples is reconciled by accounting for the mass of water in the molecular weight of $\mathrm{NHC} \cdot \mathrm{H}_{2} \mathrm{O}$. As the hydrate, $6.5 \%$ of sample mass is expected to be $\mathrm{H}_{2} \mathrm{O}$. Karl-Fischer analysis confirmed the existence of water and that it was present in the quantity predicted by the hydrate form of the intermediate (6.68 wt \%) (Fig. 9). From this analysis it is concluded that the NHC is of high purity $(>99 \%)$. 


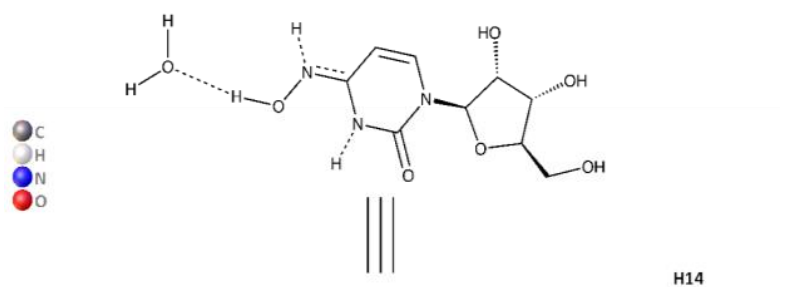

Table 3: Reaction performance remains stable upon increasing NHC reaction scale. ${ }^{\mathrm{a}}$

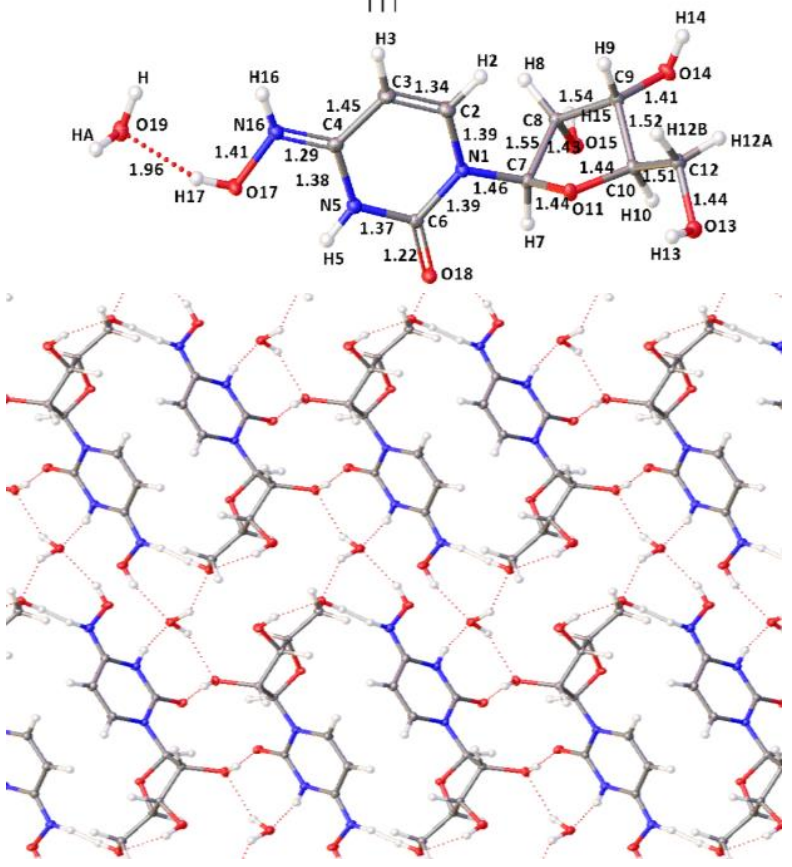

Figure 8: Single crystal X-ray analysis shows that the hydrate of NHC is formed and suggests tautomerization.<smiles>O=c1nc(NOCO)ccn1C1OC(CO)[C@@H](O)[C@H]1O</smiles>

NHC MW: $259.2 \mathrm{~g} / \mathrm{mol}$ $\mathrm{NHC} \cdot \mathrm{H}_{2} \mathrm{O} \mathrm{MW}: 277.2 \mathrm{~g} / \mathrm{mol}$ $\mathrm{H}_{2} \mathrm{O} / \mathrm{NHC} \cdot \mathrm{H}_{2} \mathrm{O}: 6.5 \%$

\begin{tabular}{cccc} 
Entry & NHC $(\mathbf{m g})$ & $\mathbf{H}_{\mathbf{2}} \mathbf{O}(\mathbf{m g})$ & $\mathbf{H}_{\mathbf{2}} \mathbf{O}(\mathbf{\%})$ \\
\hline 1 & 63.0 & 4.21 & 6.68 \\
2 & 62.0 & 4.14 & 6.67 \\
3 & 109 & 7.29 & 6.69 \\
\hline
\end{tabular}

Figure 9: Karl-Fischer analysis confirms presence of water.

\section{- N-Hydroxycytidine Hydrate: Scale-Up}

The reaction was quickly scaled over two order of magnitude with the knowledge that the NHC hydrate was of high purity (Table 3). In this manner, $500 \mathrm{~g}$ of intermediate $\mathbf{3}$ was made in short accord using a similar reaction setup as the smaller scale runs. These conditions increased the space-time yield to $48 \mathrm{~g} \cdot \mathrm{L}^{-1} \cdot \mathrm{hr}^{-1}$, a 100 -fold increase from the original version. Very little change was observed across scale ( 5 to $500 \mathrm{~g}$ ), with isolated yields between 83$85 \%$ and purity at $99-100 \mathrm{wt} \%$. Approximately $6 \%$ of $\mathrm{NHC}$ remained in the mother liquor for the $50 \mathrm{~g}$ batch giving an overall yield of $89 \%$. We thus feel confident that this reaction can be further scaled to the desired quantity, and this concluded our investigation into synthesis of NHC.

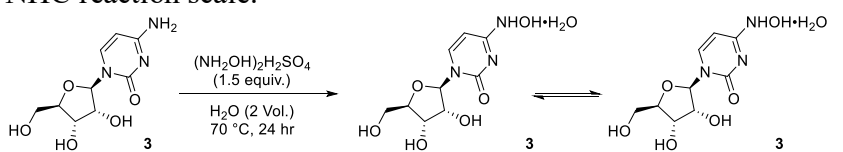

\begin{tabular}{ccccccc} 
Entry & Scale & $\begin{array}{c}\text { RB flask } \\
\text { size }\end{array}$ & $\begin{array}{c}\text { Time } \\
\text { (hr) }\end{array}$ & LCAP & $\begin{array}{c}\text { qNMR } \\
\text { purity }\end{array}$ & $\begin{array}{c}\text { Yield } \\
b\end{array}$ \\
\hline 1 & $5 \mathrm{~g}$ & $50 \mathrm{~mL}$ & 5 & 99.6 & 100 & 84 \\
2 & $10 \mathrm{~g}$ & $50 \mathrm{~mL}$ & 5 & 99.7 & 100 & 85 \\
3 & $50 \mathrm{~g}$ & $250 \mathrm{~mL}$ & 6 & 100 & 99 & 83 \\
4 & $200 \mathrm{~g}$ & $1000 \mathrm{~mL}$ & 6 & 100 & 100 & 85 \\
5 & $500 \mathrm{~g}$ & $2000 \mathrm{~mL}$ & 5 & 100 & 100 & 84 \\
\hline
\end{tabular}

a Reaction Conditions: cytidine (1 eq.), $\left(\mathrm{NH}_{2} \mathrm{OH}\right)_{2} \mathrm{H}_{2} \mathrm{SO}_{4}$ (1.5 eq.), water (2V), $70{ }^{\circ} \mathrm{C}$ and $5 \mathrm{~h}$ to $6 \mathrm{~h} .{ }^{\mathrm{b}}$ Yields are adjusted to qNMR purities.

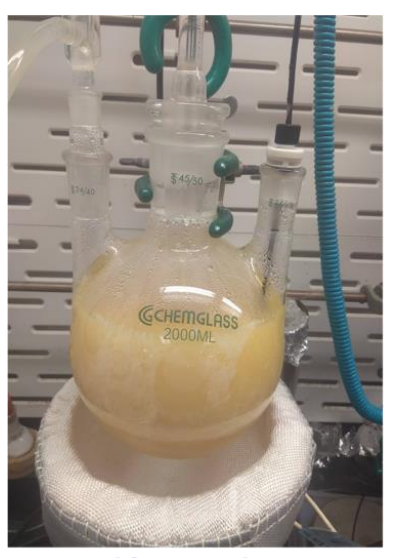

After reaction

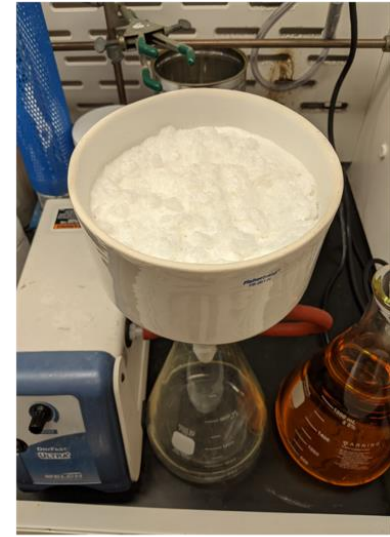

After filtration
Figure 10: Image for $0.5 \mathrm{~kg}$ reaction to produce 3 after completion and product after filtration.

\section{- Molnupiravir: Reaction Optimization, Impurity Profile, and Mechanistic Analysis}

In our preliminary report, we disclosed that NHC could be selectively esterified on the primary alcohol in preference to the $N$ hydroxy or secondary alcohol acylation. A number of challenges remained in order for the reaction to be pragmatically run. The maximum assays for desired product were slightly above $80 \%$ LCAP, enzyme loading was very high (200 wt $\%)$, a large excess of 1,4-dioxane as solvent was used (60 volumes), and product was isolated by column chromatography.

Solvents were quickly screened, and 2-methyl THF was identified as a suitable and environmentally preferable alternative to 1,4-dioxane. Throughput and sustainability were greatly enhanced by running the reaction as a slurry and decreasing solvent to 2-5 volumes, and reducing enzyme loading to $20 \mathrm{wt} \%$ eliminated a cost barrier. However, less molnupiravir was obtained under these conditions and production plateaued at $70 \%$ LCAP under these conditions. 
a)

\section{Reaction Progress By Time \\ (200 wt\% Enzyme, 60 Vol 2-MeTHF)}

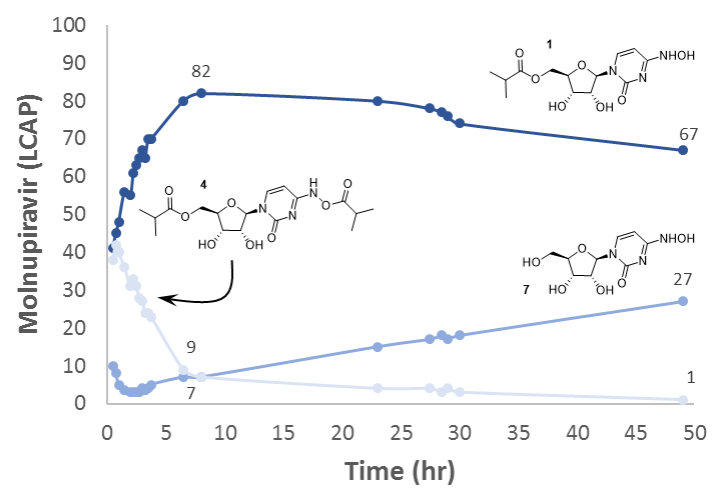

$\multimap$ NHC $\rightarrow$ Molnupiravir $\rightarrow$ Molnupiravir Oxime Ester

b) Reaction Progress By Time (20 wt\% Enzyme, 5 Vol 2-MeTHF)

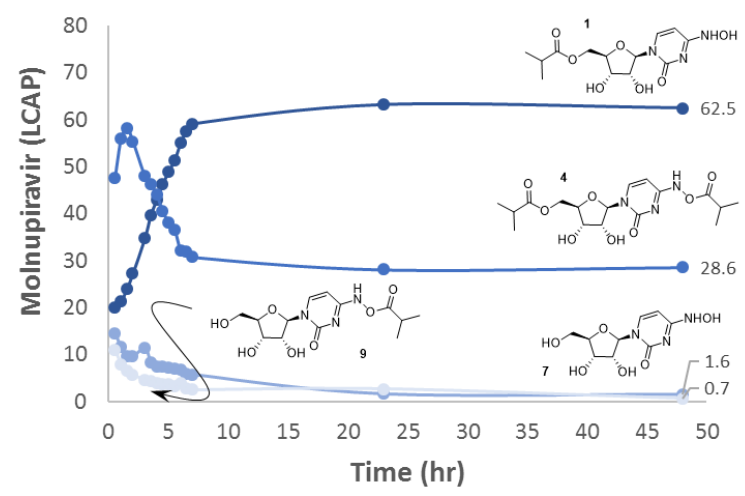

$\rightarrow$ Molnupiravir $\rightarrow$ Molnupiravir Oxime Ester $\longrightarrow$-NHC $\longrightarrow$ NHC Oxime Ester

Figure 11: Reaction profile as a function of time shows unexpected trends in impurity profile.

We sought better fundamental understanding of the reaction system in order to make further improvements. Monitoring the reaction as a function of time provided some of these insights (Figure 11). Several impurities were observed, identified, and tracked. The following conclusions emerged:

1. Molnupiravir reaches a maximum point at $8 \mathrm{hr}(84 \%$ LCAP), and then rate of degradation exceeds that of product formation. This results in decreasing levels of molnupiravir and increasing levels of NHC (Fig. 11a).

2. NHC is mostly consumed with 3 hours ( $3 \%$ LCAP); however, after this point NHC levels begin to rise as it is regenerated (Fig. 11a).

3. The over-acylated product $\mathbf{4}$, molnupiravir isobutyryl oxime ester, is generated in large quantities early in the course of the reaction. This intermediate decays as the reaction progresses.

4. Smaller quantities of $N$-hydroxycytidine isobutyryl ester (9) are observed early in the reaction, and this intermediate also decreases with time (Fig. 11b).

5. Using lower enzyme loading results in a more stable reaction profile (Fig. 11b).

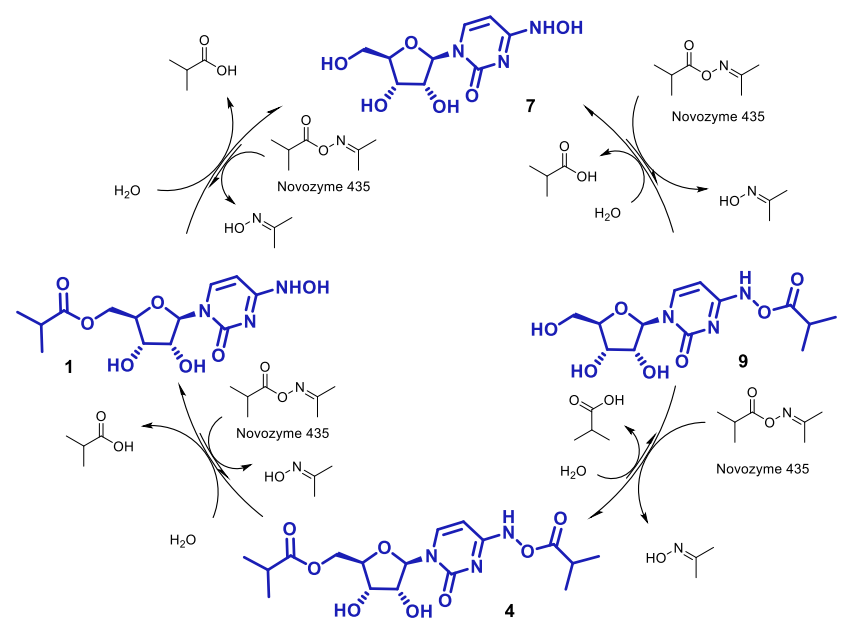

Figure 12: Postulated mechanism of esterification.

It seems reasonable to postulate that the reaction is a series of equilibria based on acyl-transfer (Fig. 12). Acylation of the $\mathrm{N}$ hydroxy group appears to be fast and likely occurs first, forming a short lived intermediate, 9. This oxime ester is essentially an acyltransfer reagent similar to acetone isobutyryl oxime ester. Following formation of the NHC oxime ester, a second esterification occurs, at the site of the primary alcohol to give a diacylated intermediate, molnupiravir isobutyryl oxime ester 4. The oxime ester is then cleaved to give molnupiravir, 1. Alternatively, the NHC isobutyryl oxime ester can be reverted to NHC. The primary alcohol is then acylated by either a second equivalent of oxime ester from acetone or from the NHC oxime ester to give molnupiravir The ester of molnupiravir can be cleaved to reform NHC, 7, but this reaction is slower than cleavage of the oxime esters. We speculate that formation of the oxime ester is the kinetic but not thermodynamic product, and that cleavage of oxime esters is the driving force of the reactions. Generation of acetone oxime is observed in the course of the reaction.

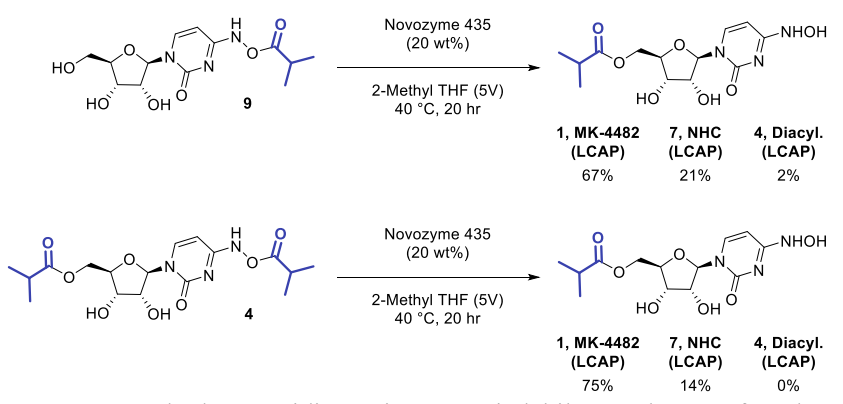

Figure 13: $N$-hydroxycytidine oxime ester is labile, can be transferred to primary alcohol, and is cleaved in preference to ester.

This hypothesis is supported by two additional observations (Fig. 13). First, molnupiravir is formed when NHC isobutyryl oxime ester 9 is exposed to enzyme, even in the absence of acetone isobutyryl oxime ester and no diacylated $\mathbf{4}$ is observed. Secondly, molnupiravir is again formed, when molnupiravir oxime ester $\mathbf{4}$ is in the presence of enzyme, but in the absence of acetone isobutyryl oxime ester.

Initial exploration of purification conditions via crystallization revealed that the highly polar NHC was the most difficult impurity to purge. Based on the difficulty in rejecting NHC, and the ease of eliminating the diacylated material, we surmised that it would be 
Table 4: Exploration of reagents shows that oxime ester can be selectively cleaved, increasing molnupiravir yield.
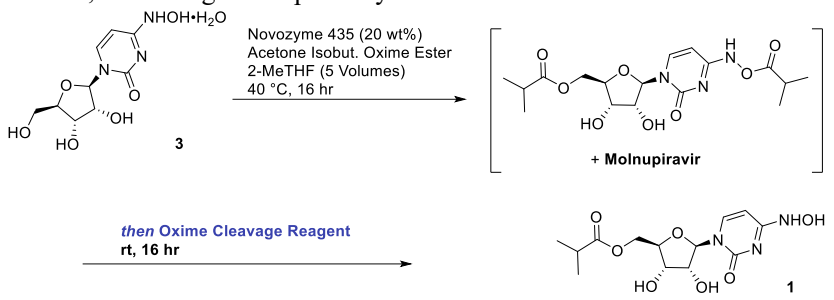

\begin{tabular}{ccccc} 
Entry & $\begin{array}{c}\text { Cleavage } \\
\text { Reagent }\end{array}$ & $\begin{array}{c}\text { 7, NHC } \\
\text { (LCAP) }\end{array}$ & $\begin{array}{c}\text { 1, EIDD } \\
\text { (LCAP) }\end{array}$ & $\begin{array}{c}\text { 4, Diacyl. } \\
\text { (LCAP) }\end{array}$ \\
\hline
\end{tabular}

$1^{\mathrm{a}}$

3

70

20

2

$\mathrm{H}_{2} \mathrm{O}$

3

71

19

3

$\mathrm{MeOH}$

3

4

$\mathrm{EtOH}$

4

70

69

19

$5 \mathrm{NH}_{3}$ in $\mathrm{EtOH}$

4

$6 \quad \mathrm{NH}_{4} \mathrm{OH}$ (aq.)

10

$7 \quad \mathrm{NH}_{2} \mathrm{OH}$ (aq.)

84

86

92

0

3

2

a Product distribution prior to addition of cleavage reagent.

best to operate in a reaction regime which minimized NHC content. Unfortunately, when NHC is minimized the reaction mixture has very high molnupiravir oxime ester levels ( $>20 \%$ LCAP), cutting into the reaction yield (Fig. 11b).

Though the yield under these conditions appears low, we wondered whether the diacylated material could be directly converted to molnupiravir (Table 4). The oxime ester bond seems to be easily cleaved. Perhaps a chemical agent could be added to the reaction mixture for this purpose. Probing this concept, a variety of oxime ester cleaving agents were added to molnupiravir oxime ester 4 to study material balance upon reaction. External alcohols showed little activity in cleaving the oxime ester (entries 1-3); however, nitrogeneous additives showed substantial activity. Use of ammonia led to elevated levels of NHC, an undesired outcome. Selection of aqueous hydroxylamine was quite selective for reaction with oxime ester in preference to the primary ester (Entry 7). In fact, molnupiravir content increased from 66\% LCAP to a value just over $92 \%$ LCAP.

\section{- Scale-up to $100 \mathrm{~g}$}

Possessing excellent reaction outcome, attention turned to scaleup (Table 5) and isolation (Figure 14) of the API from reaction solution. Water was the only solvent identified which purged NHC while affording sufficient recovery of product. Fortunately, selection of water as a crystallization solvent for crude reaction mass returned material of excellent quality, and water did not cleave the ester to an appreciable extent. Examination of the mother liquor showed that some material was lost in filtration however $(17.7 \%)$. This remains an opportunity for further improvement, and perhaps the use of antisolvent or salting effects will improve recovery. The overall yield of reaction was $93 \%$ with an isolated yield of $71 \%$. The reaction was scaled two orders of magnitude to $100 \mathrm{~g}$ with very similar results.

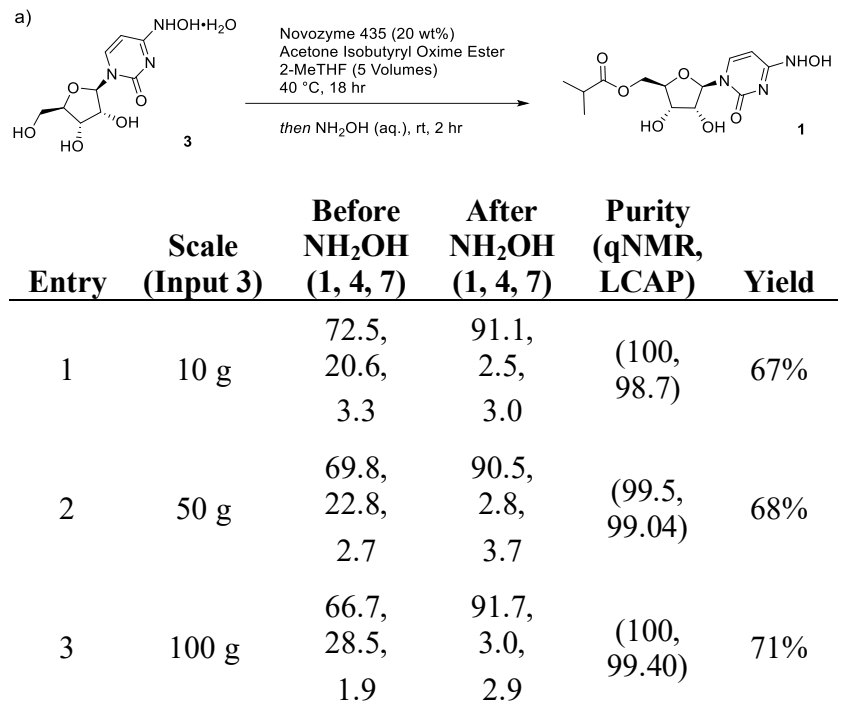

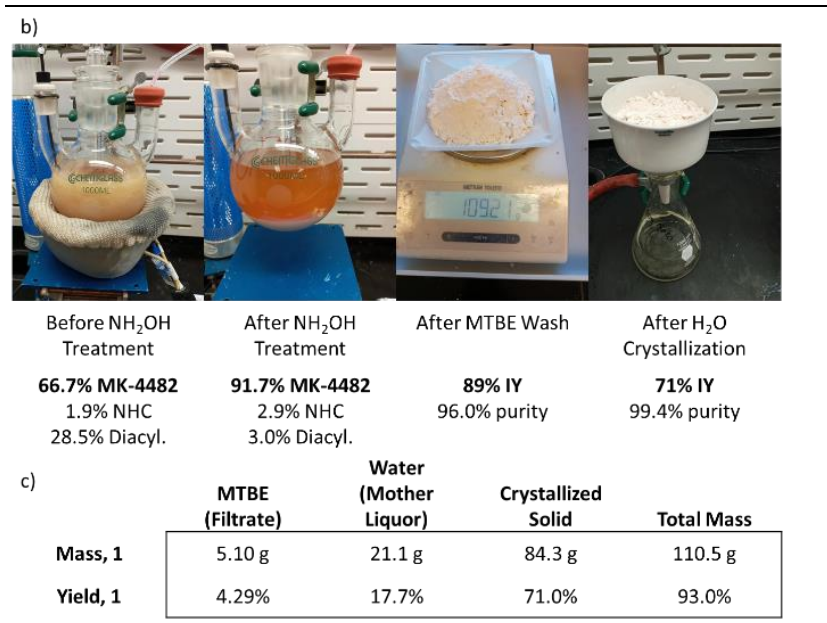

Figure 14: a) Scale-up, b) product distribution, and c) mass balance for 100 $\mathrm{g}$ reaction.

\section{Conclusions}

In summary a practical, two-step route to molnupiravir from highly available cytidine was developed. The reaction features high yields and simple purification protocols which can be performed at scale. Reactions are run at high concentration with environmentally friendly solvents. Further room for improvements remains possible. Based on the selective cleavage of oxime ester with hydroxylamine, it appears a non-enzymatic acylation may be possible through degradation of a diacylated intermediate. Additionally, even higher yields are likely to be obtained as recovery of API in crystallization is enhanced.

\section{ASSOCIATED CONTENT}

\section{Supporting Information}

The Supporting Information is available free of charge on the ACS Publications website including experimental details. 


\section{AUTHOR INFORMATION}

\section{Corresponding Author}

* David Snead

Medicines for All Institute

737 N 5th St.

Box 980100

Richmond, Virginia 23298

E-mail: drsnead@vcu.edu

\section{Author Contributions}

${ }^{\dagger}$ D.J.P. and N.V contributed equally and conducted chemical development work toward NHC and MK-4482.

S.A. conducted market research on cytidine.

A.L.K. prepared substrates for mechanistic studies.

F.S.C.P. aided studies toward purification MK-4482.

J.M.B., D.W.C., and R.W.S developed analytical HPLC methods for NHC and MK-4482.

D.R.S. guided research.

\section{Notes}

The authors declare no competing financial interests.

\section{ACKNOWLEDGMENT}

We thank the Bill and Melinda Gates Foundation for their longstanding support of our research. At BMGF, we express gratitude to Trevor Laird and John Dillon for their thoughtful commentary and suggestions. We also thank Silpa Sundaram and Dr. Susan Hershenson for fostering an ecosystem where innovation can thrive. This work was partially supported by Structural Biology resources provided by National Institutes of Health Shared Instrumentation Grant S10OD021756 (MKS) and Virginia General Assembly Higher Education Equipment Trust Fund (HEETF) to VCU.

\section{REFERENCES}

1. Sheahan, T.P.; Sims, A.C.; Zhou, S.; Graham, R.L.; Pruijssers, A.J.; Agostini, M.L.; Leist, S.R.; Schafer, A.; Dinnon III, K.H.; Stevens, L.J.; Chappel, J.D.; Lu, X.; Hughes, T.M.; George, A.S.; Hill, C.S.; Montgomery, S.A.; Brown, A.J.; Bluemling, G.R.; Natchus, M.G.; Saindane, M.; Kolykhalov, A.A.; Painter, G.; Harcourt, J.; Tamin, A.; Thornburg, N.J.; Swanstrom, R.; Denison, M.R.; Baric, R.S. Sci. Transl. Med., 2020, 12, eabb5883.

2. Cox, R.M.; Wolf, J.D.; Plemper, R.K. Nat. Microbiol., 2021, 6, 11 18.

3. a) Salganik, R.I.; Vasjunina, E.A.; Poslovina, A.S.; Andreeva, I.S. Mutat. Res., 1973, 20, 1-5. b) Halford, B. Chem. Eng. News 2020, 98, 22. c) Cross, R. Chem. Eng. News 2020, 98, 12.

4. a) Vasudevan, N.; Ahlqvist, G.P.; McGeough, C.P.; Paymode, D.J.; Cardoso, F.S.P.; Lucas, T.; Dietz, J.-P.; Opatz, T.; Jamison, T.F.; Gupton, F.B.; Snead, D.R. Chem. Commun., 2020, 56, 13363-13364. b) Gopalsamuthiram, V.; Williams, C.; Noble, J.;
Jamison, T.F.; Gupton, B.F.; Snead, D.R. Synlett, 2020, 31, A-C. c) Steiner, A.; Znidar, D.; Ötvös, S.B.; Snead, D.R.; Dallinger, D.; Kappe, C.O. Eur. J. Org. Chem., 2020, 6736-6739.

5. a) Painter, G.R.; Bluemling, G.R.; Natchus, M.G.; Guthrie, D. WO2019113462, 2018. b) Painter, G.R.; Perryman, D.; Bluemling, G.R.WO2019173602, 2019.

6. Data taken from analysis of India import/export records.

7. Benkovics, T.; McIntosh, J.; Silverman, S.; Kong, J.; Maligres, P.; Itoh, T.; Yang, H.; Huffman, M.; Verma, D.; Pan, W.; Ho, H.-I.; Vroom, J.; Knight, A.; Hurtak, J.; Morris, W.; Strotman, N.; Murphy, G.; Maloney, K.; Fier, P. ChemRxiv, 2020, posted on 12/22/2020. (DOI: 10.26434/chemrxiv.13472373.v1)

8. a) Morell, S.A.; Lipton, S.H.; Alexander, F. US2844514, 1958. b) Einosuke, O.; Koichi, O.; Yukio, S.; Seizi, I.; Masahiko, Y.; Yoshio, N.; Ikuo, S. US3168446, 1965. c) Yoshio, T.; Tadao, T.; Tetsuya, K.; Hisao, M.; Masaharu, Y.; Takehiko, I. US3201388, 1965. d) Jingkang, Z. CN1271080, 2006. e) Zhang, J.; Ding, N.; Liu, Y. CN102212096, 2011.

9. a) Suzuoki, Z.; Akira, K.; Katsuharu, Y. US3231385, 1966. b) Gil, A.; Valverde, L. US4544559, 1981. c) Ogoshi, S. US4758553, 1988. d) Leary, H.L.; Burns, R.A. WO1998006277, 1998. e) Masor, M.L.; Leach, J.L.; Molitor, B.E.; Benson, J.D.; Baxter, J.H. US5492899, 1996. f) Masor, M.L.; Leach, J.L.; Molitor, B.E.; Benson, J.D.; Baxter, J.H. US5700590, 1997.

10. Kinichiro, S.; Masajiro, K.; Akira, K. US3104171, 1963.

11. a) Bobby, A.H.; Eugene, L.S. GB1200582, 1970. b) Hamada, Y.; Yoshino, M. US3686392, 1972. c) Shinzato, I.; Sato, H.; Toride, Y.; Takeuchi, M. US6777396, 2002. d) Van de Ligt, C.P.A.; Cook, D.A.; Newcomb, M.D. US7326424, 2008. e) Jiadong, C.; Xiaochun, C.; Xiaoquan, H.; Shuya, L.; Bing, S.; Yiwen, T.; Lei, Z. CN102987169, 2013.

12. a) Bergmeyer, H.; Haid, E.; Nelboeck, H.M.; Weimann, G. US3787392, 1974. b) Leishan, C.; Liping, S.; Yan, W.; Ran, X. CN105693798, 2016.

13. Communicated in private correspondence. Contact corresponding author if help is needed connecting with potential cytidine suppliers.

14. Yongjun, L.; Guang, Y.; Jian, Z.; Jun, Z.; Weiqi, Z. CN107365812, 2017.

15. Li, F.; Xiong, Y. CN101717420, 2010.

16. Asahi, S.; Tsunemi, Y.; Doi, M. US4839285, 1989.

17. Tsunemi, Y.; Asahi, S.; Doi, M. US4880736, 1989.

18. a) Henning, G. GB486366, 1938. b) Henning, G. CH215401, 1941.

19. Chen, N.; Fan, X.; Ge, Y.; Hu, C.; Li, Y.; Ma, Q.; Song, X.; Wu, S.; Xie, X.; Xu, Q.; Zhang, C. AU2019101117, 2020.

20. a) Kinichiro, S.; Akira, K. US3223592, 1965. b) Louis, L.; Sidney, G. US3303100, 1967. c) Doncheck, J.A.; Millis, J.R.; Swanson, P.E. US5204245, 1993.

21. a) Brown, D.M.; Hewlins, M.J.E.; Schell, P. J. Chem. Soc., 1968, 1925-1929. b) Lee, G.C.Y.; Prestegard, J.H.; Chan, S.I. J. Am. Chem. Soc., 1972, 94, 951-959. 